\title{
High Performance Computing
}

National Cancer Institute

\section{Source}

National Cancer Institute. High Performance Computing. NCI Thesaurus. Code C18149.

Refers to a class of evolving technologies that provide leading-edge computational capabilities. Includes scalable high performance computers, high end graphic systems, and high speed networks. Used for molecular modeling, genome analysis, and image processing, among others. 